\title{
In Vivo Lighted Fluorescence via Fenton Reaction: A New Approach for Imaging of Hydrogen Peroxide in Living Systems
}

\author{
Changhui Liu, ${ }^{\dagger, \$}{ }^{\S}$ Weiju Chen,${ }^{\S}$ Zhihe Qing, ${ }^{\dagger} * *$ Jing Zheng, ${ }^{\S}$ Yue Xiao, ${ }^{\S}$ Sheng Yang, ${ }^{\dagger}$ \\ Lili Wang, ${ }^{\S}$ Yinhui Li, ${ }^{\S}$ and Ronghua Yang ${ }^{\dagger, \$, *}$
}

${ }^{\dagger}$ School of Chemistry and Biological Engineering, Changsha University of Science and Technology, Changsha, 410004, P. R. China;

Department of Chemistry and Environmental Engineering, Hunan City University, Yiyang, 413000, P. R. China;

${ }^{\S}$ State Key Laboratory of Chemo/Biosensing and Chemometrics, College of Chemistry and Chemical Engineering, Hunan University, Changsha, 410082, P. R. China

*To whom correspondence should be addressed: E-mail: Yangrh@pku.edu.cn, qingzhihe@hnu.edu.cn; Fax: +86-731-8882 2523. 
Instruments. ${ }^{1} \mathrm{H}$ NMR spectra were recorded on a bruker DRX-400 spectrometer using TMS as an internal standard. Liquid chromatography-mass spectrometry (LC-MS) analyses were performed using an Agilent $1100 \mathrm{HPLC}$ MSD spectrometer. Transmission electron microscopy (TEM) images were obtained with a JEOL-3010 instrument. Zeta potential experiments and dynamic light scatting (DLS) measurements were performed by ZetaSizer Nanoseries. Fourier transform infrared (FT-IR) spectra were obtained from a TENSOR 27 spectrometer (Bruker Instruments Inc., Germany). Small-angle powder X-ray diffraction patterns (XRD) were obtained in a Scintag XDS-2000 powder diffractometer. Nitrogen adsorption-desorption isotherm was obtained on a Micromeritics ASAP 2010 Sorptometer. All fluorescence measurements were performed on a PTI QM4 Fluorescence System (Photo Technology International, Birmingham, NJ). Confocal laser scanning microscopy (CLSM) images were obtained on a Fluo View ${ }^{\mathrm{TM}}$ FV 1000 (Olympus, Japan). MTT assay was obtained a Benchmark Plus (Bio-Rad Instruments Inc., Japan). In vivo images were acquired using an IVIS Imaging System (Lumina xr). The $\mathrm{pH}$ was measured by a model $868 \mathrm{pH}$ meter (Orion).

Synthesis of Perylene Tetracarboxylic Acid Diimide Dimmer (PTAD). Perylene dimethylamine (PTCDI) was prepared according to the literature (Wang, B.; Yu, C. Angew. Chem. Int. Ed. 2010, 49, 1485-1488). Then, perylene dimethylamine (50 mg, $0.089 \mathrm{mmol}$ ) was dissolved in $2.5 \mathrm{~mL}$ of toluene, then $50 \mu \mathrm{L}$ of 1,2-dibromoethane $(0.577 \mathrm{mmol})$ was added to the solution and the reaction mixture was refluxed for $5 \mathrm{~h}$ under nitrogen atmosphere. Finally, PTAD was gained in $42.6 \%$ yield by filtering, washing with ether, followed drying under vacuum. ${ }^{1} \mathrm{H}$ NMR (400 MHz, DMSO-d $\left.{ }_{6}, \mathrm{TMS}\right): \delta 8.78$ (d, $\left.J=8.1,8 \mathrm{H}\right), 8.46$ (d, $J=8.3$, $8 \mathrm{H}), 6.1-5.62(\mathrm{~m}, 8 \mathrm{H}), 4.1(\mathrm{~d}, J=7.8,8 \mathrm{H}), 2.91-3.06(\mathrm{~m}, 12 \mathrm{H}), 2.33-2.67(\mathrm{~m}, 12 \mathrm{H}), 2.09$ (s, 12H); ESI-MS: $m / z 575.2\left(\mathrm{M}^{2+} / 2\right)$ 。

Cell Culture. HeLa cells and A549 cells were grown in Dulbecco's modified Eagles medium (DMEM) supplemented with $10 \%$ fetal bovine serum and $100 \mathrm{U} / \mathrm{mL} \quad 1 \%$ 
penicillin/gentamicin at $37{ }^{\circ} \mathrm{C}$ under $5 \% \mathrm{CO}_{2}$ atmosphere. HEK 293 cells were cultured in DMEM supplemented with only $10 \%$ fetal bovine serum at $37{ }^{\circ} \mathrm{C}$ under $5 \% \mathrm{CO}_{2}$ atmosphere.

MTT Assays. HeLa cells $\left(2 \times 10^{5}\right.$ cells per well $)$ were dispersed in 96-well microtiter plates and maintained at $37{ }^{\circ} \mathrm{C}$, in $5 \% \mathrm{CO}_{2}$ for $24 \mathrm{~h}$. Then HeLa cells were incubated with the nanosphere $(0.1 \mathrm{mg} / \mathrm{mL})$ at different concentrations for $24 \mathrm{~h}$. Next, the cell culture medium was removed, following the addition of MTT solution $(5 \mathrm{mg} / \mathrm{mL})$ to each well. After $4 \mathrm{~h}$, the remaining MTT solution was removed, followed by supplementation with $150 \mu \mathrm{L}$ of DMSO to each well to dissolve the formazan crystals. Absorbance was measured at $490 \mathrm{~nm}$ in a Triturus microplate reader.

Characterization of the Cell-endocytosed Nanosphere by Transmission Electron Microscopy. HeLa cells were treated with the nanosphere $(0.1 \mathrm{mg} / \mathrm{mL})$ for $2 \mathrm{~h}$ at $37{ }^{\circ} \mathrm{C}$. After washing and centrifugation, the cell pellets were fixed with $2.5 \%$ glutaraldehyde in $0.1 \mathrm{M}$ PBS for $2.5 \mathrm{~h}$, dehydrated using an serial concentrations of alcohol $(20 \%, 40 \%, 60 \%, 80 \%$, and $100 \%$ twice) for $20 \mathrm{~min}$, and then embedded in Araldite resin at $65^{\circ} \mathrm{C}$ overnight. A $70 \mathrm{~nm}$ section was placed on a TEM grid and stained with saturated uranyl acetate and $0.2 \%$ Reynolds lead citrate before TEM imaging.

Animals Culture. Athymic BALB/c nude mice were purchased from the Changsha SLAC Laboratory Animal Co. Ltd. and maintained under pathogen-free conditions. To establish tumor xenografts, $5 \times 10^{6}$ in vitro-propagated HeLa cells (in $100 \mu \mathrm{L}$ of PBS buffer) were injected s.c. into the back of $18 \sim 20$ g nude mice. All animal operations were performed in accordance with institutional animal use and care regulations, according to protocol No. SYXK (Xiang) 2008-0001, approved by the Laboratory Animal Center of Hunan. Once the tumors had grown to a volume of $\sim 100 \mathrm{~mm}^{3}$, they were ready for the in vivo imging. All animals were acclimated to the animal facility for at least $48 \mathrm{~h}$ prior to experimentation. 
Table S1. Physicochemical properties of MSN, MSN-F $\mathrm{DNA}_{\mathrm{DA}}$ and $\mathrm{Fc} @ \mathrm{MSN}-\mathrm{F}_{\mathrm{DNA}} / \mathrm{PTAD}$.

\begin{tabular}{cccc}
\hline Particles & Surface area $\left(\mathrm{m}^{2} / \mathrm{g}\right)$ & Pore Volume $\left(\mathrm{cm}^{3} / \mathrm{g}\right)$ & Pore Size $(\mathrm{nm})$ \\
\hline MSN & 1057.8 & 0.832 & 3.06 \\
MSN-F & 614.5 & 0.623 & 2.60 \\
Fc@MSN-F & 222.3 & $/$ & $/$ \\
\hline
\end{tabular}
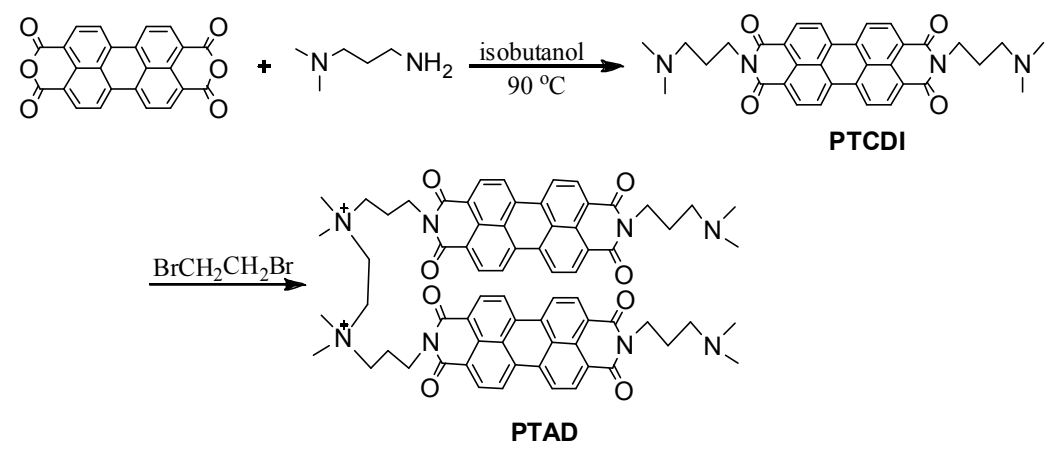

Figure S1. Synthetic route for PTAD.
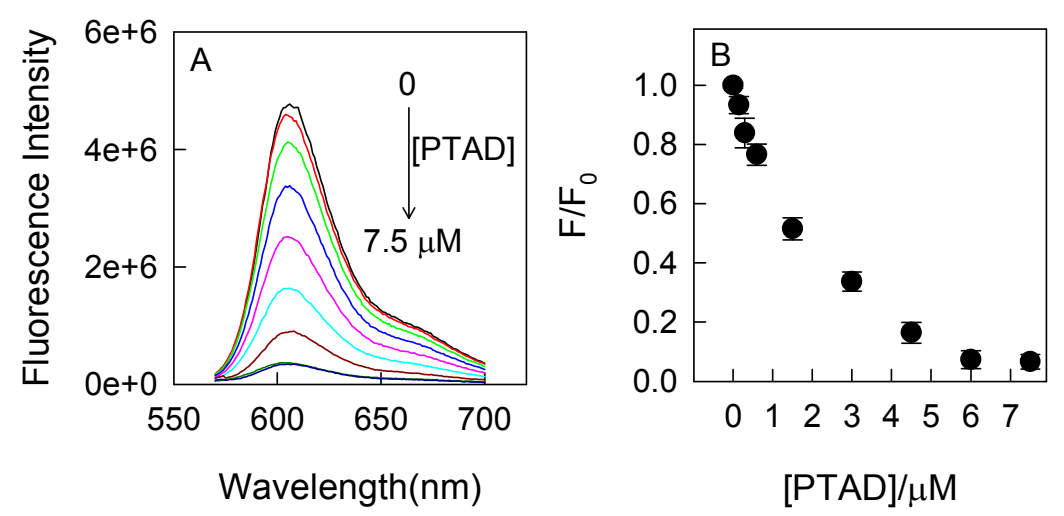

Figure S2. (A) Fluorescence emission spectra $\left(\lambda_{\mathrm{ex}}=560 \mathrm{~nm}\right)$ of $\mathrm{F}_{\mathrm{DNA}}(0.25 \mu \mathrm{M})$ upon incubation with various amounts of PTAD $(0,0.15,0.3,0.6,1.5,3.0,4.5,6.0,7.5 \mu \mathrm{M})$ in Tris- $\mathrm{HCl}(20 \mathrm{mM}, \mathrm{pH}$ 7.2) at room temperature. (B) The corresponding fluorescence changes upon addition of PTAD in Tris- $\mathrm{HCl}$ buffer $(20 \mathrm{mM}, \mathrm{pH}=7.2) . F_{0}$ and $F$ are the fluorescence intensities of $\mathrm{F}_{\mathrm{DNA}}$ at $610 \mathrm{~nm}\left(\lambda_{\mathrm{ex}}=560 \mathrm{~nm}\right)$ before and after treatment with PTAD. Error bars indicate s.d. $(n=3)$. 


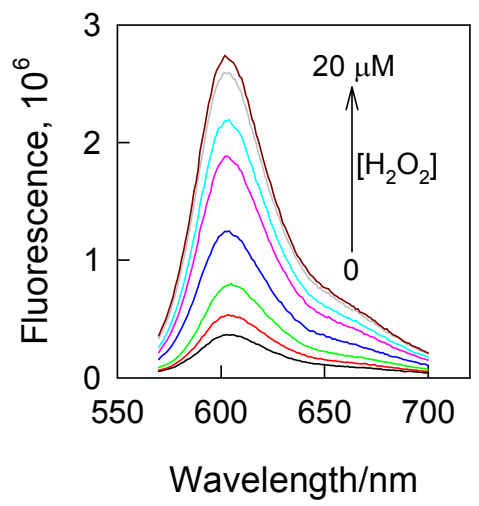

Figure S3. Fluorescence emission spectra $\left(\lambda_{\mathrm{ex}}=560 \mathrm{~nm}\right)$ of $\mathrm{F}_{\mathrm{DNA}} / \mathrm{PTAD}$ upon incubation with $\mathrm{Fe}^{2+}(20 \mu \mathrm{M})$ and various amounts of $\mathrm{H}_{2} \mathrm{O}_{2}(0,0.50,1.0,2.0,5.0,10,15,20 \mu \mathrm{M})$ in Tris- $\mathrm{HCl}$ (20 mM, pH 7.2) at $25^{\circ} \mathrm{C}$.

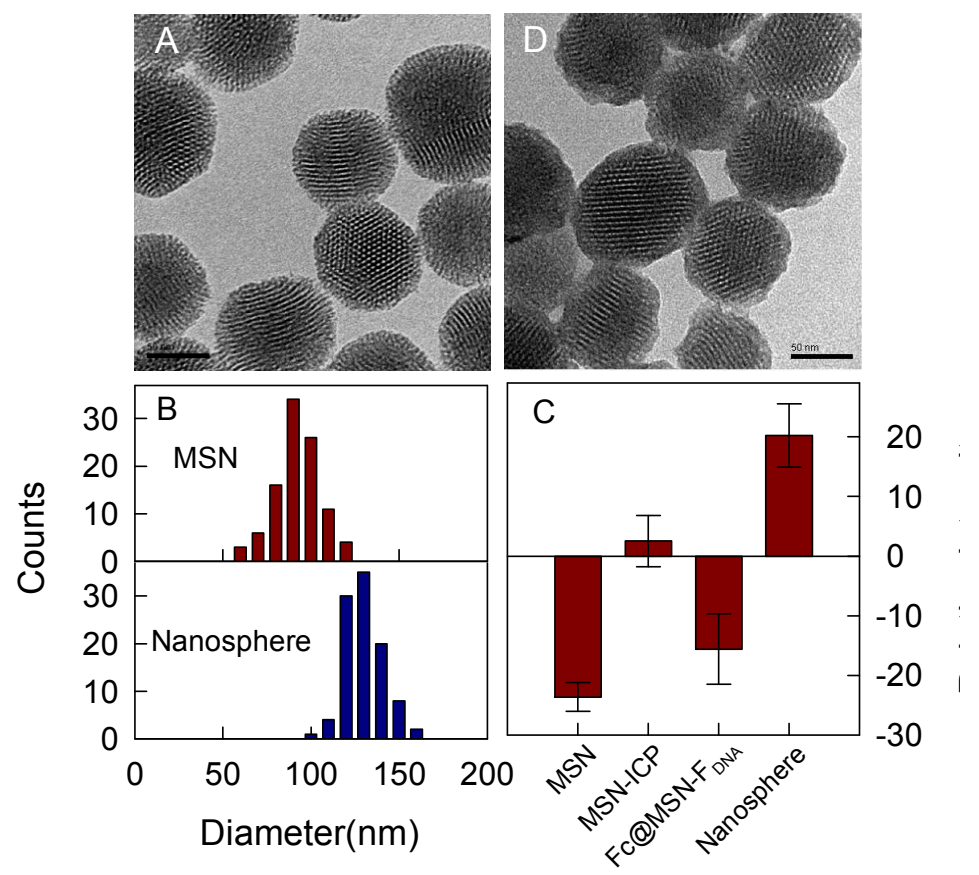

Figure S4. TEM images of the as-synthesized MSN (A) and the nanosphere (D); (B) DLS data of MSN and the nanosphere; (C) Zeta potential of MSN, MSN-ICP, MSN-F ${ }_{\mathrm{DNA}}$, and the nanosphere in Tris-HCl buffer solution (20 mM, $\mathrm{pH} 7.2)$. 

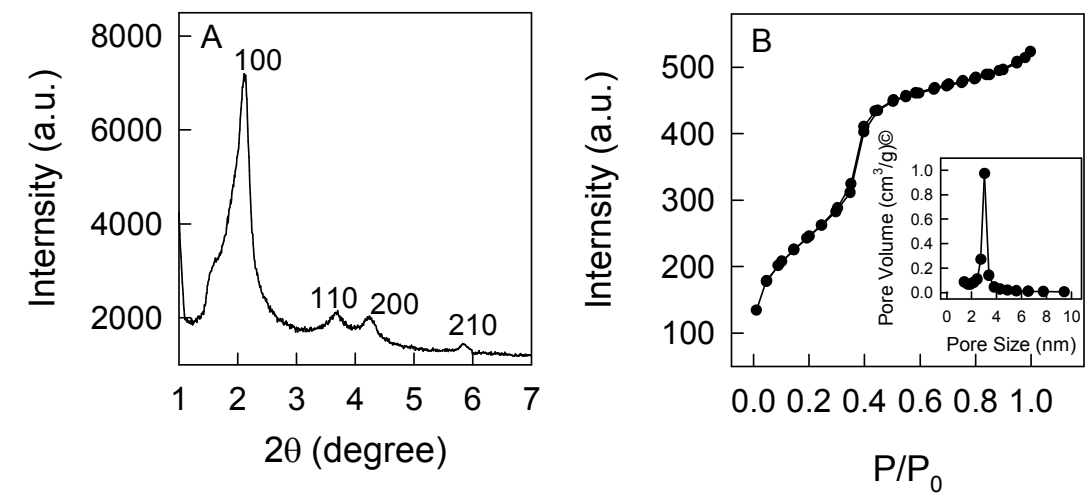

Figure S5. (A) Low angle powder X-ray diffraction patterns (XRD) and (B) Nitrogen adsorption-desorption isotherms of MSN. Insert: pore size distribution curves of MSN.

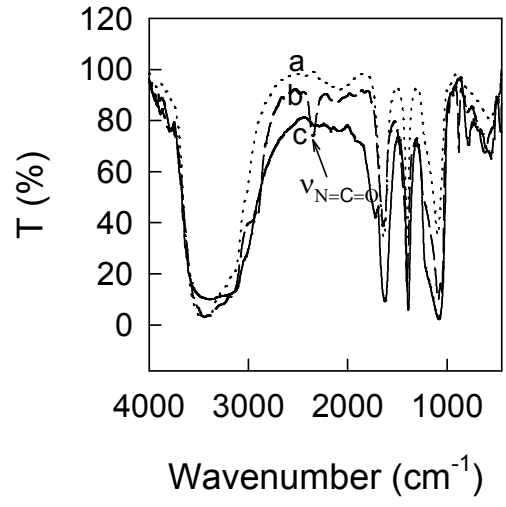

Figure S6. FT-IR spectra of the as-synthesized MSN (a), MSN-ICP (b), and MSN-F DNA $_{\text {(c) }}$ 


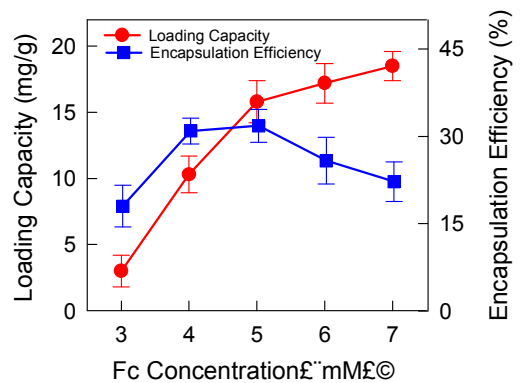

Figure S7. Loading capacity (LC) and encapsulation efficiency (EE) for ferrocene loaded in MSN at different concentrations of stock solutions. The amount of loaded ferrocene was determined by potentiometric titration. With increasing initial weight of ferrocene, the LC is continuously increased, while the EE increases firstly and decreases. Encouragingly, a high $\mathrm{LC}$ of $15.8 \mathrm{mg} / \mathrm{g} \mathrm{SiO}_{2}$ and a maximum EE of near $31.8 \%$ can be achieved for MSN at $30 \mathrm{mg}$ $\mathrm{mL}^{-1}$.

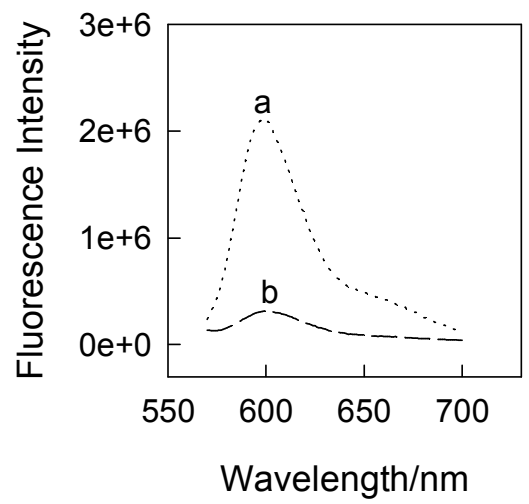

Figure S8. Fluorescence emission spectra of Fc@MSN-F $\mathrm{FNA}_{\text {DNA }}\left(\lambda_{\mathrm{ex}}=560 \mathrm{~nm}\right)$ before (a) and after (b) treatment with PTAD in Tris- $\mathrm{HCl}(20 \mathrm{mM}, \mathrm{pH}$ 7.2). 


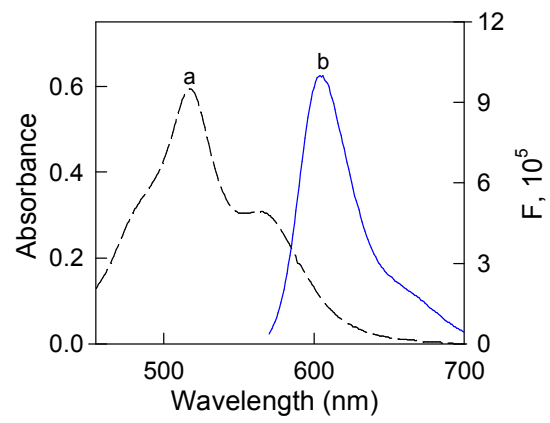

Figure S9. UV-visible absorption spectrum of PTAD (trace a) and fluorescence emission spectra of Fc@MSN-F $\mathrm{DNA}_{\mathrm{DA}}\left(\right.$ trace b, $\left.\lambda_{\mathrm{ex}}=560 \mathrm{~nm}\right)$ in Tris- $\mathrm{HCl}(20 \mathrm{mM}, \mathrm{pH} 7.2)$.
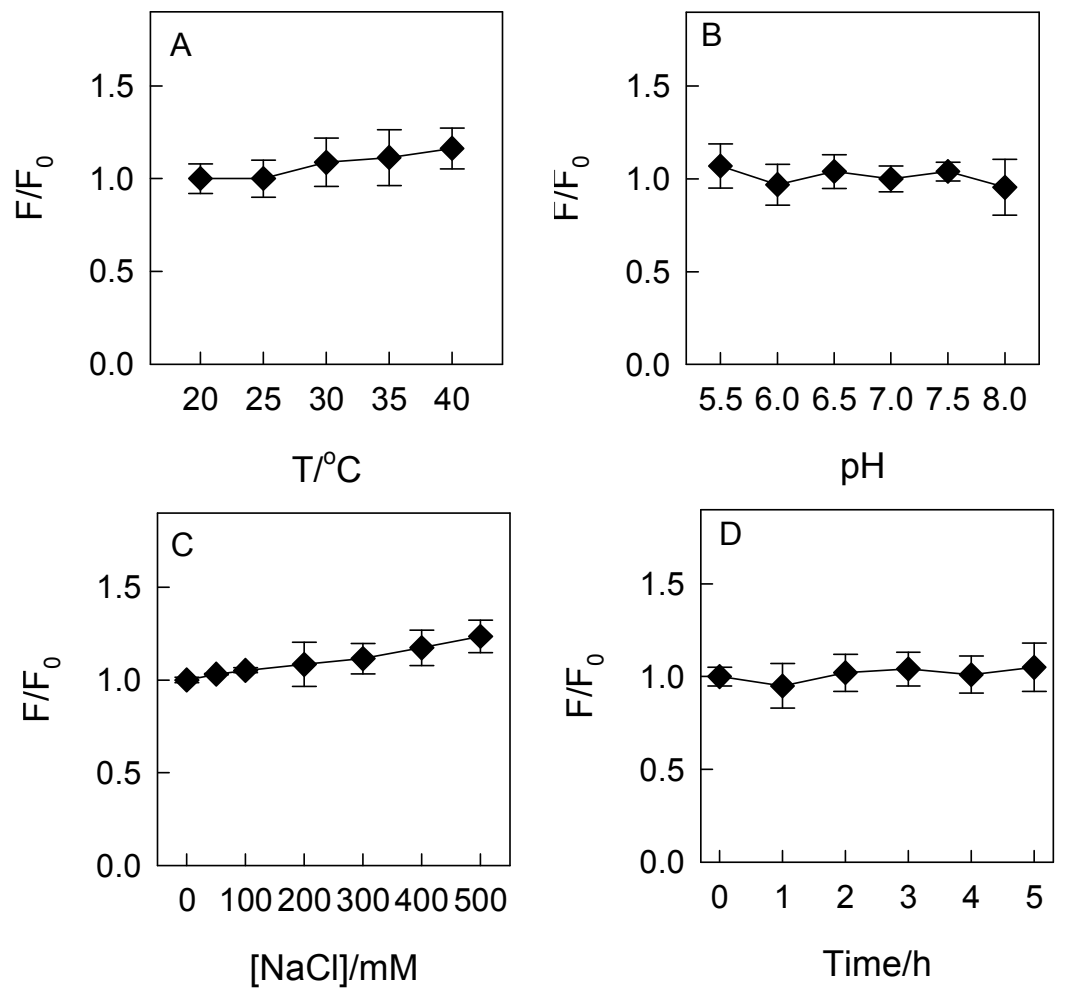

Figure S10. The stability of the nanosphere. Fluorescence intensity of the nanosphere $(0.1$ $\mathrm{mg} / \mathrm{mL}$ ) at biological temperature (A), biological $\mathrm{pH}$ range (B) and various ionic concentration (C). (D) Fluorescence intensity of the nanosphere $(0.1 \mathrm{mg} / \mathrm{mL})$ in cell culture media containing $10 \%(\mathrm{v} / \mathrm{v})$ fetal bovine serum for different time at $37{ }^{\circ} \mathrm{C}$. Error bars indicate s.d. $(\mathrm{n}=3)$. 

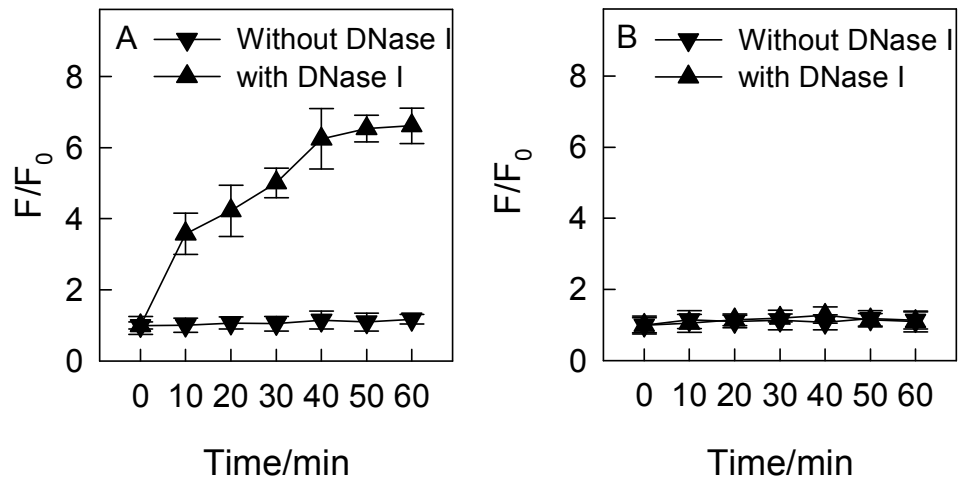

Figure S11. The protective effect of the nanosphere on DNA against nuclease-mediated degradation. Fluorescence emission spectra $\left(\lambda_{\mathrm{ex}}=560 \mathrm{~nm}, \lambda_{\mathrm{em}}=610 \mathrm{~nm}\right)$ of $\mathrm{F}_{\mathrm{DNA}} / \mathrm{PTAD}(\mathrm{A})$ and the nanosphere (B) upon incubation with $3 \mathrm{U} / \mathrm{mL}$ DNase I in Tris-HCl (20 mM, pH 7.2) for different time, Where $F_{0}$ is the fluorescence intensity at the start of the degradation reaction, $F$ is that at the corresponding time point.

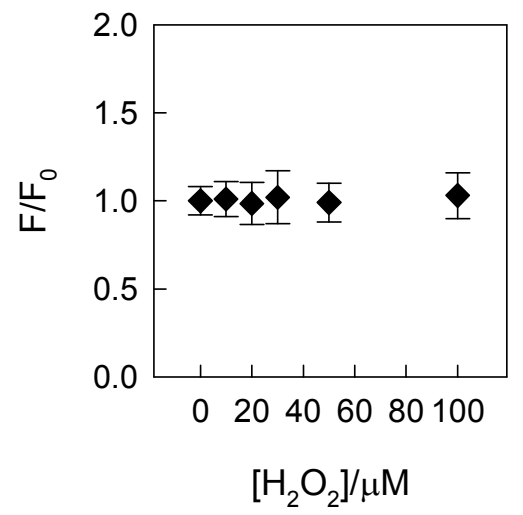

Figure S12. Fluorescence intensity of $\mathrm{MSN}-\mathrm{F}_{\mathrm{DNA}} / \mathrm{PTAD}$ in the presence of $\mathrm{H}_{2} \mathrm{O}_{2}$ at different concentrations. Data were collected after treatment with $\mathrm{H}_{2} \mathrm{O}_{2}$ for 0.5 h. Error bars indicate s.d. $(\mathrm{n}=3)$. 

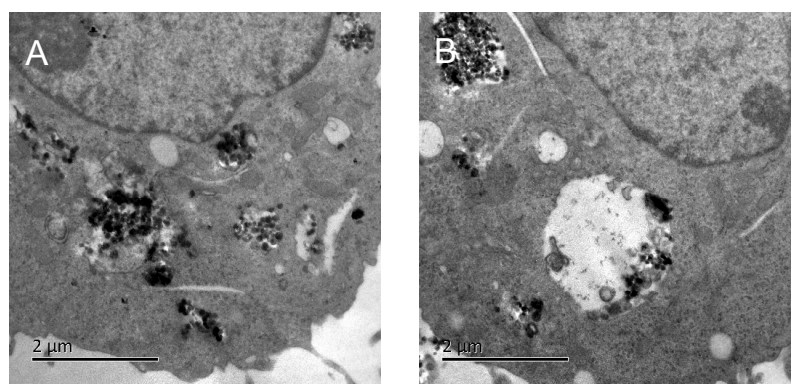

Figure S13. TEM micrographs of the nanosphere (balck dot) endocytosed by HeLa cells (A) and HEK 293 cells (B).

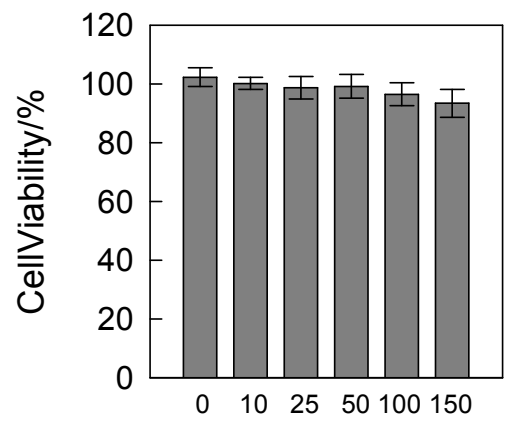

[Fc@MSN-F $\left.{ }_{\text {DNA }} / P T A D\right](\mu \mathrm{g} / \mathrm{mL})$

Figure S14. Cell viability of HeLa cells incubated with different concentrations of the nanosphere for $24 \mathrm{~h}$. Cells without treatment by nanosphere were taken as the control, and the viability was set as 100\%. Error bars indicate s.d. $(n=3)$. 